http://dx.doi.org/10.4314/ejotmas.v7i1-2.8

\title{
AN EXAMINATION OF THE PLACEMENT OF ADVERBIALS IN THE ACADEMIC WRITING OF FRESH UNDERGRADUATE STUDENTS IN THE UNIVERSITY OF CAPE COAST, GHANA
}

\author{
*Prof. Philip Arthur GBORSONG, Ph.D. \\ **Anita B. APPARTAIM
}

\begin{abstract}
Rules have been formulated on how adverbials are used. Such rules as stated by Quirk and Greenbaum (1973), Hornby (1975) and Swan (1995) are silent on how a few adverbials that have no restrictions regarding their position and order in sentences should be used. This paper, relying on language variation in the second language setting as a theoretical framework, explored how undergraduate students used these kinds of mobile adverbials. The quantitative research design and a simple random sampling were applied to select a total of 100 essays and exercises from fresh undergraduates of the University of Cape Coast, Ghana. Analysing these essays and exercises, we concluded that although the adverbial is an optional clausal element, the undergraduate students used it in providing further information on the other clausal elements. In addition, the undergraduate students often placed the adverbials in the mid position of their sentences.
\end{abstract}

Keywords: Adverbials, GE, Undergraduate students, Clausal elements, Effective communication

\section{Introduction}

The entrenchment of English in the entire socio-political and economic set up of Ghana is, perhaps, most noticeable in the field of education. English is introduced to the school-going Ghanaian child right from the nursery stage and is taught up to the university level. This means educated Ghanaians get a wide exposure to the learning of English at all levels of education so that they can express themselves in diverse

*Prof. Philip Arthur GBORSONG, Ph.D. is of the Department of Communication Studies, University of Cape Coast, Ghana

Email: pgborsong@yahoo.com

**Anita B. APPARTAIM is of the Department of English, University of Cape Coast, Ghana Email: anita.agyepong@ucc.edu.gh 
ways in English. One important area in the use of English is in writing composition which enhances the English language competence of the educated person.

Of the five clausal elements in English, the verb $(\mathrm{V})$ is the most important since it is what is required for the effective communication of thought. It is an obligatory element and, therefore, in most cases cannot be left out of a construction. The subject (S) element of structure is also obligatory. However, there are a number of constructions in which it may be omitted. The object $(\mathrm{O})$ is also an obligatory element of structure though its presence or otherwise depends on the type of verb used in the construction. The complement (C) is, perhaps, very much like the object in importance, as it cannot be omitted when copular or intensive verbs are used. The element that appears to be of the least importance is the adjunct/adverbial (A). It is not required for the expression of thought even though it adds information. Despite the fact that it is often optional, it has a unique characteristic; it is mobile. It has the capacity to begin a sentence, be somewhere in the middle or come at the end of it. Its mobility in a sentence sometimes leads to various interpretations of the sentence. In this article, we intend to explore the positioning of the adjunct in essays written by fresh university students.

The general characteristic feature of the adverbial to be mobile is the issue of concern in this study. The fact is that rules have been formulated in connection with the order in which different types of adverbials are used. According to Swan (1995), manner adverbials usually come after the verb. Quirk and Greenbaum (1973), Hornby (1975) and Swan (1995) agree that when two or more different types of adverbials occur in a construction, they are arranged in a specified order. When we consider where users of English frequently place those adverbials that have no restriction whatsoever, grammar books appear to be silent. This silence is a gap that needs to be filled in scholarship. The purpose of this study is an attempt at establishing the view that although the adverbial is mobile and that a lot of adverbials have no constraints in connection with their positional placement, undergraduates frequently prefers to place such adverbs in one of the three positions. This study also, establishes whether the students frequently place mobile adverbials in the initial, medial or final position. It is our hope that this study provides useful information in an area where almost all grammar books are silent. We, also, hope that the media, lecturers, editors and textbook writers find the research findings useful. 


\section{Adverbial Categories}

Quirk and Greenbaum (1973) identify ten adverbial categories according to their functional classification. These are manner, time, place, result, reason, purpose, condition, concession, comparison and circumstance. Hornby (1975) and Gborsong (2012) list adverbials of manner, time, place, degree, interrogative, frequency, direction and duration. Graver (1998) mentions eight. His list agrees with that of Quirk and Greenbaum except that he excludes 'circumstance' and 'concession'. Thomson and Martinet (1988) also mention eight adverbial categories. Their list introduces 'degree' and "relative" adverbials.

For the purpose of this work, six adverbial categories are used. These are adverbials of manner, frequency, time, place and direction, degree and the sentence adverbials. The assumption is that users appear to be conversant with these categories of adverbial and so can handle the second research instrument (consisting of an exercise on adverbials) better. We shall agree with Swan (1995) and Hornby (1975) as well as Gogovi et al. (2011), who talk of three positions of the adverbials. We shall, also, use the three terminologies of these authors given as Front position, Mid position and End position.

\section{Research Questions}

The paper has tried to find answers to such questions as:

(a) Do undergraduate students in the University of Cape Coast use the various categories of adverbials?

(b) Do they demonstrate awareness of the rules governing the placement of this specific category of adverbials?

(c) Does the awareness, if any, cover the order in which more than one adverbial that occur in the same position are arranged? These will actually prepare the way for the most important question;

(d) Where, in the sentence, do undergraduate students of the University of Cape Coast prefer to place mobile adverbials?

\section{Theoretical and Methodological Considerations}

Naji et al. (2019) have expressed that there are 'exciting and innovative literature' written in different varieties of English in many parts of the world, non-native Englishes not excluded. They express that 'standard language' is now considered a myth and even suggest a reimagining of such classics as Austen and Shakespeare to fit the new literature evolving. This statement is in tandem with the theory chosen for the study. The theoretical pivot of the phenomenon that produced the 
concept of new Englishes is that of language variation and change. Weinreich $(1953 ; 1968)$ presented an objective framework for categorizing the mutual influence and 'mixing' that takes place when languages come in contact. Since then several linguists, sociolinguists and anthropological linguists have observed and analysed this phenomenon in different parts of the world.

Each of the new Englishes has distinct features, as well as distinct linguistic and cultural identities, largely as a result of the different historical, geographical, political and socio-cultural factors that gave birth to them. Thus, Ghanaian English differs from either Nigerian or Indian English. Each variety, however, also has various sub-varieties or dialects, reflecting its multilingual environment. The depth of impact at various linguistic levels in each variety is determined by the degree of localization of the English spoken. The unique characteristics of new Englishes pose several problems, among which are those of definition, identification, classification, norm and intelligibility. The designation 'Ghanaian English' for instance, is somehow deceptive: does a Ga speaker of Ghanaian English (GE) use English exactly the same way as an Ashanti, or Ewe speaker? If the answer is in the negative - which happens to be the case in this instance - then the next question is: what then constitutes Ghanaian English? The arguments advanced by both language specialists and teachers of language indicate that there is really no consensus opinion yet as to what constitutes Ghanaian English. The opinions range from an outright rejection of its existence, to those who take its existence for granted and use the term without defining or questioning it. In between these two extremes is a continuum of various definitions, descriptions and analyses.

In his keynote address at the inaugural meeting of the Ghana English Studies Association, which was held at the University College of Education, Winneba, from June 13-15, 1996, and published, 1997, Professor Ayo Bamgbose outlined six approaches to the description of Non-Native Variety of English (NNVE) including The Deviation Approach; The Common Core Approach; The Comparative Approach and The Sociolinguistic Approach. The first of the Approaches sees non-native varieties as deviations from the standard. As such, NNV's can only be viewed in light of the native varieties. They are often regarded as stigmatized varieties that are barely acceptable to the native speakers and are generally avoided by the local educated nonnative users of the language. Bamgbose appropriately names these the negative approaches (Bamgbose 1997, p.13). The approach which gives the Non-Native Variety (NNV) a definite recognition is the Sociolinguistic Approach. This approach, which Ghanaians subscribe 
to, views the NNV essentially in its functional role. Bamgbose terms this the positive approach.

Therefore, we begin this study from the standpoint that educated Ghanaians speak the English Language in a peculiar way to reflect the socio-cultural milieu from which they come. The study of the peculiar usage of adverbials, therefore, examines the subject from the functional viewpoint. We also endeavour to adopt, as much as possible, methods that emphasize the function of the samples that are collected. We are convinced that since English is a second language in Ghana, educated Ghanaian speakers will of necessity (or perhaps rather by instinct) need to be creative if they are to express their views, narrate and describe phenomena effectively, especially considering their socio-cultural backgrounds. Their peculiar usage will be unacceptable, sometimes sound quaint or simply interesting especially in direct comparison with the native varieties. Obviously, peculiar usage, including the dropping of the adverb particle or the preposition component of a phrasal verb that we here attempt to investigate is creative but involves violating the standard norms. At a forum on the use of English, Owusu-Ansah (1997, p. 23) pointed out that the socio-cultural conditions under which English operates in the 'outer circle' make it inevitable for a departure from the exornormative standards of the native varieties. Although these varieties were still aimed at in teaching the language, setting new norms involved breaking old norms.

As far as Bamgbose is concerned, the question of whether there is a Ghanaian or Nigerian English (NE) should not arise, since it is a known fact that in language contact situations, a second language (L2) is bound to be influenced by its linguistic environment. He buttresses his argument with the fact that the existence of different Englishes has a wide acceptance among linguists internationally. He identifies three different approaches to usages in NE as the interference, the deviation and creativity approaches. The first approach traces NE usages to influences from local languages (i.e., from 'interferences' from the mother tongue - L1). The problem with this approach, Bamgbose contends, is that it fails to recognize the fact that not all forms of interference can validly be considered as coming from the L1, since some of them might be coming from Nigerian Pidgin English (NPE), which he does not consider to be an L1 Second, it ignores the normal processes of language development such as semantic extension and the creation of new idioms, which cut across all L1 backgrounds. The second approach involves a comparison with 'native English,' thus, labelling all differences from this model as 'deviant.' Bamgbose's contention with this approach is that it ignores the fact that certain typical NE usages are the result of creativity. The 
third is the creativity approach, which focuses on the resources of local languages as well as English language (EL) to create new expressions and idioms. This approach, in his judgment, has the added advantage of recognizing the autonomous status of NE. He warns, nonetheless, that not all NE usages can be said to have arisen out of linguistic creativity.

Bamgbose's conclusion is that whereas each of the above approaches sheds some light on the nature of NE, none of them is the solely adequate criterion to characterize the entire spectrum of NE. $\mathrm{He}$, therefore, proposes a combination of all three approaches. He also raises the often-recurrent issue of how and where to draw the line between usages that are genuinely Nigerian in nature and those that are outright errors of usage. Finally, he poses yet another difficult methodological and sociolinguistic question: whose usage is to be seen as the model or standard? His answer is that the model should not be that of the purist who sees all usages not in conformity with the British model as a deviation and a corruption, but rather opts for what he calls the "natural and spontaneous usage of the local educated Nigerian user of English" (1982, p.105). The main problem with this proposition is that Bamgbose does not really qualify what he means by 'educated Nigerian user of English'; especially since he himself recognizes that there are different levels of education. The issues raised by Bamgbose, however, are to a large extent representative of what many other language analysts have discussed at varying degrees and levels.

The features that have been proposed as identifying characteristics of NE are mostly similar in nature at the levels of phonetics and phonology, syntax, lexis and semantics; discourse, speech acts and stylistics. These features share a lot of common ground with those of the new Englishes advanced by Kachru (1982; 1992) and several others. According to most of the contributors and analysts of the Nigerian situation, Nigerian writers have been some of the major contributors to the standardization of NE. The issue of intelligibility has also been variously dealt with in Ghana. Afrifa et al. (2019); Dako (2017); Nkansah (2017); Ngula (2014); Appartaim (2012); Lomotey (2010); have tackled Ghanaian English and indelibility of NE in terms of Ghanaianism, acceptability and pronunciation. It is so accepted that it is now a language used in the home of many Ghanaians as a sort of $L_{1}$ (Afrifa et al., 2019). The most representative opinion on this, however, is that NE is indigenous to Nigeria and its most basic usage is intra-national, which it does well. On the question of international intelligibility, the opinion is that standard NE is to a large extent intelligible and that whatever difficulties encountered along those lines are not peculiar to NE alone, but also to the users of all the 
other varieties of EL worldwide. The difficulties encountered by the NE speaker communicating with an American English speaker will be similar in many respects to that encountered by a Ghanaian English speaker communicating with a New Zealander.

Another issue touched upon is that of language attitudes. The opinion of most analysts seems to be that NE does not yet have full acceptance among Nigerians, although the reasons advanced have been mostly non-linguistic in nature. This unfavourable attitude might be attributed to the activities of purists who feel the recognition of an NE will spell doom for EL in Nigeria. Numerous linguistic data abound, with sound theoretical arguments, to prove the existence of a localized and acculturated form of EL that can be safely referred to as Nigerian English. Not minding the arguments of purists, however, more and more people are beginning to recognize and to have a positive attitude towards NE although it may still take a while before it receives wide acceptance among the general populace. The following quote from Adekunle (1985, p. 36) is quite revealing and appropriate at this point.

The English language has, as a result of many years of active use in the Nigerian speech community, ... become part of Nigeria's contemporary environment and behaviour. [...] It is an artefact whose foreign derived components have in the process of its evolution combined with native Nigerian elements to make it local. (Adekunle 1985:36)

Kendall (2018) argues that it is inevitable to have different Englishes due to the global spread of it. This spread she indicates is evident in African countries and cites examples of how Nigeria has a Nigerian English and further sub-varieties of it. The reason for this is that language evolves and is moved by economic gains as exemplified in the Nigerian as well as Ghanaian contexts. This goes to confirm that there will not be one type of English, but varieties will exist as long as there are different dialects of a variety of language. Kachru (1992) has described EL in terms of three concentric circles: the Inner Circle, the Outer Circle and the Expanding Circle. According to this classification, Ghanaian English, Nigerian English for instance belong to the Outer Circle, defined by Kachru as regions of the world that were formerly colonized by Britain and the US, where EL was the language of empire building. In this circle, societal penetration has resulted in the development of different sub-varieties, depending on the geographical, cultural and linguistic contexts. The identifying 
features of these varieties given by Kachru include elements from phonology, grammar, lexis, collocations, idioms, discourse and style, code-mixing and code-switching, and a lack of homogeneity. The features of these so-called "non-native institutionalized varieties" of EL (NNIVE) as identified by Kachru are the following:

a) An extended range of uses in the sociolinguistic context;

b) There is an on-going process of nativization of the registers and styles;

c) There is a body of nativized EL literature with formal and contextual characteristics marking it as localized.

Platt et al. (1984) also believe that for any variety of EL to qualify as a 'New English' it must fulfil the following criteria:

1) It must have been taught as a subject as well as used as a medium of instruction in places where languages other than EL were the main languages;

2) It has developed in an area where a native variety of EL was not the language spoken by most of the population;

3) It is used for a range of functions among those who speak or write it in the region where it is used;

4) It has become 'localized' or 'nativized' by adopting some language features of its own, such as sounds, intonation patterns, sentence structures (and that is what this study sought to do), words and expressions. Usually it has also developed some different rules for using language in communication.

A combination of the two criteria above gives us a more finetuned picture of the defining features of New Englishes. A close examination of these characteristic features shows that GE easily fits into this category of English Language. A quick glance at Ghanaian creative writing especially the works of such well-known authors as Ama Ata Aidoo and Ayi Kwei Armah serves to buttress this assertion. Some research has been conducted in the area of adverbial use in Ghana and beyond. A few of such literature is reviewed. Outside Ghana, we find Truelson's (2017) paper which identified how adverbials were placed in translated literary and non-literary texts in Swedish and English. The study was further concerned with whether there was meaning change as a result of the translation. Some of the findings were that there was not much difference in meaning in both the fiction and non-fiction translations and that the preferable positions of adverbs in both the English and Swedish translations was at the end of the sentence. 
In Ghana, Quansah and Tetteh (2017) conducted a study into the use of adverbs at the junior high school level in Ghana. The major theory backing their research was the 'Skinner's behaviourist theory of language learning although they further also touched on Kachru's concentric circles on New Englishes. Their data were collected from pupils from the Ashanti Region through a stratified random sampling. They concluded that learning facilities' accessibility by teachers was a great enhancer to teachers' delivery and students' language acquisition. Further, Awuku (2011) conducted a study on the placement of adverbials in the Ewe language focusing on the 'role and reference grammar theory. A finding of his was the placement was similar to that found in the English language. Having laid some foundation and a framework for GE, we now proceed to show, using data drawn from various students' writing how adverbials are placed in sentences used by Ghanaian students.

\section{Data Presentation and Analysis}

Two main sources of data were explored for this study. First, the communicative skills examination essays written by fresh students at the end of the second semester, 2014/2015 constitute the data for this study. Apart from that, the fresh students were asked to read a set of sentences carefully and indicate by a tick (ü) in the gap, where they preferred to place the adverbials. A total of one hundred fresh undergraduate students were selected from four faculties in the University of Cape Coast.

The purpose of the task was threefold. First, it was to test the students' knowledge of the adverbial categories. Second, we wanted to explore their awareness of the rules of placement and arrangement of two similar or different adverbials in the same position. Third, we wanted to verify the students' placement preference of mobile adverbials. To begin with, twenty simple sentences, making use of six adverbial categories were used. The sentences were grouped into three. The first group of six sentences were designed to test students' knowledge of the categories of adverbials (Brown and Miller, 1994; Tregido, 1988). The students were required to match the six sentences with the six adverbial categories given. For example,

We usually have our breakfast at the restaurant.

The second group of three sentences were designed to test students' knowledge of the order in which they arranged similar adverbials and two different adverbial types that occur at the same position. The sentences were paired and the students were to indicate which pair had the adverbials correctly arranged. For example, 
He comes every day to the lecture.

The next ten sentences had three gaps each; Front, Mid and End positions. The students had to insert in the gaps provided, the adverbials according to the positions the students preferred. For instance,

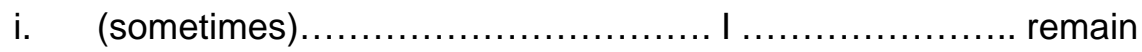
indoors

ii. (certainly) ....................... Aba could ................ have done it

iii. (Honestly) ................. Musa ................... didn't get the money

iv. I went to study in the library (after lunch).

v. (Honestly), Musa didn't get the money.

The quantitative method of analysis was used for all the three sections. In the case of the identification of adverbial types and the arrangement of two adverbials that occur in the same position, there was tabular arrangement of scores according to sex. The result of the third section which is the most important aspect of the work was also stated in a tabular form and the grand total for both male and female students was presented in a histogram and a pie chart for easy reference.

\section{Results and Discussion}

\section{Identification of Adverbial Types}

The first six exercises of the task tested the students' knowledge of specific adverbial categories. The test items focused on manner, frequency, time, degree, sentence and place adverbials. Each sentence had only one adverbial type and the students were asked to name the type. The table below shows the result according to gender and the totals.

Table 1: A table showing students' knowledge of Adverbials according to gender

\begin{tabular}{llllllll}
\hline SCORE & $6 / 6$ & $5 / 6$ & $4 / 6$ & $3 / 6$ & $2 / 6$ & $1 / 6$ & TOTAL \\
MALE & 22 & 12 & 8 & 6 & 2 & 0 & 50 \\
FEMALE & 28 & 16 & 5 & 1 & 0 & 0 & 50 \\
TOTAL & 50 & 28 & 13 & 7 & 2 & 0 & 100 \\
\hline
\end{tabular}

As the table above indicates, twenty-eight females out of the fifty and twenty-two males of out of the fifty could identify the types of 
adverbs correctly while twelve males and sixteen females could not identify one adverbial form correctly. In all none of the students could be said not to know anything about adverbials. This indicates that all the students had a fair knowledge about the types of adverbials in English language.

\section{Adverbials in the Same Position}

In this section there were four test items numbered $7-11$. The first two had adverbials of place and the next two, of time respectively at 'end position' for the students to arrange in the proper order. The result is given in the table below:

Table 2: A table showing students' knowledge of Adverbials order

\begin{tabular}{|l|l|l|l|l|l|l|}
\hline SCORE & $\mathbf{4 / 4}$ & $\mathbf{3} / \mathbf{4}$ & $\mathbf{2 / 4}$ & $\mathbf{1 / 4}$ & $\mathbf{0 / 4}$ & TOTAL \\
\hline Male & 20 & 18 & 10 & 2 & 0 & 50 \\
\hline Female & 23 & 22 & 5 & 0 & 0 & 50 \\
\hline Total & 43 & 40 & 15 & 2 & 0 & 100 \\
\hline
\end{tabular}

\section{Placement Preference of Mobile Adverbials}

This section constitutes the most important aspect of the whole exercise. Ten examples each of the mobile adverbials of manner, frequency, time and sentence were given. Against each example was a sentence with gaps at the front, mid and end positions. The students had to read each sentence carefully and indicate which position the given adverbial should go. For the purpose of the analysis, only the first of each of the four adverbial types were chosen. The ones chosen were consistently used for all the one hundred students. Table 3 below is a representation of the result. 
Table 3: A table showing students' placement of Adverbials

\begin{tabular}{|c|c|c|c|c|c|c|c|c|c|c|c|c|}
\hline \multirow[t]{2}{*}{$\begin{array}{l}\text { ADVERBIAL } \\
\text { TYPE }\end{array}$} & \multicolumn{3}{|c|}{$\begin{array}{l}\text { FRONT } \\
\text { POSITION }\end{array}$} & \multicolumn{3}{|c|}{ MID POSITION } & \multicolumn{3}{|c|}{ END POSITION } & \multicolumn{3}{|c|}{ TOTAL } \\
\hline & $\mathrm{M}$ & $\mathrm{F}$ & Total & $M$ & $\mathrm{~F}$ & Total & $\mathrm{M}$ & $F$ & Total & $M$ & $\mathrm{~F}$ & Total \\
\hline Manner & 5 & 5 & 10 & 29 & 25 & 54 & 16 & 20 & 36 & 50 & 50 & 100 \\
\hline Frequency & 10 & 10 & 20 & 33 & 28 & 61 & 17 & 12 & 29 & 50 & 50 & 100 \\
\hline Time & 10 & 9 & 19 & 37 & 30 & 67 & 3 & 11 & 14 & 50 & 50 & 100 \\
\hline Sentence & 17 & 16 & 33 & 15 & 23 & 38 & 18 & 11 & 29 & 50 & 50 & 100 \\
\hline Total & 42 & 40 & 82 & 114 & 106 & 220 & 54 & 54 & 108 & 200 & 200 & 400 \\
\hline
\end{tabular}

\section{Quantitative Analysis}

In order to have an objective view of the results, we looked at the data quantitatively. We, thus, converted into the percentages for the various positions. From the table, out of the four hundred uses of the four adverbial types by the hundred students, eighty-two (82) were in the front position, two hundred and twenty (220) went to the mid position and a hundred and eight (108) occurred in the end position. The formula for finding the percentage is:

$$
\frac{\ddot{A}}{400} \times \frac{100}{1}
$$

where delta Ärepresents the frequency count for the various positions. The computation, therefore, is as follows:

(a) Front Position

$$
\begin{aligned}
\ddot{\mathrm{A}} & =82 \\
\% & =\frac{82 \times 100}{400} \\
& =20.5 \% \\
\ddot{\mathrm{A}} & =\frac{220}{400} \\
\% & =55 \%
\end{aligned}
$$

(b) Mid Position:

(c) End Position:

$$
\begin{aligned}
\ddot{\mathrm{A}} & =108 \\
\% & =\frac{108 \times 100}{400} \\
& =27 \%
\end{aligned}
$$

From the percentage computed, it can be inferred that the undergraduate students frequently preferred to place mobile adverbials in the mid position. This means the mobile adverbial may be placed anywhere after the subject and before the main verb in a declarative construction. The observation is illustrated in a histogram based on 
the result. The X-axis has the percentages at intervals of 10 per cent and ranges from zero (0) to sixty 60 . The positions are placed on the Y-axis.

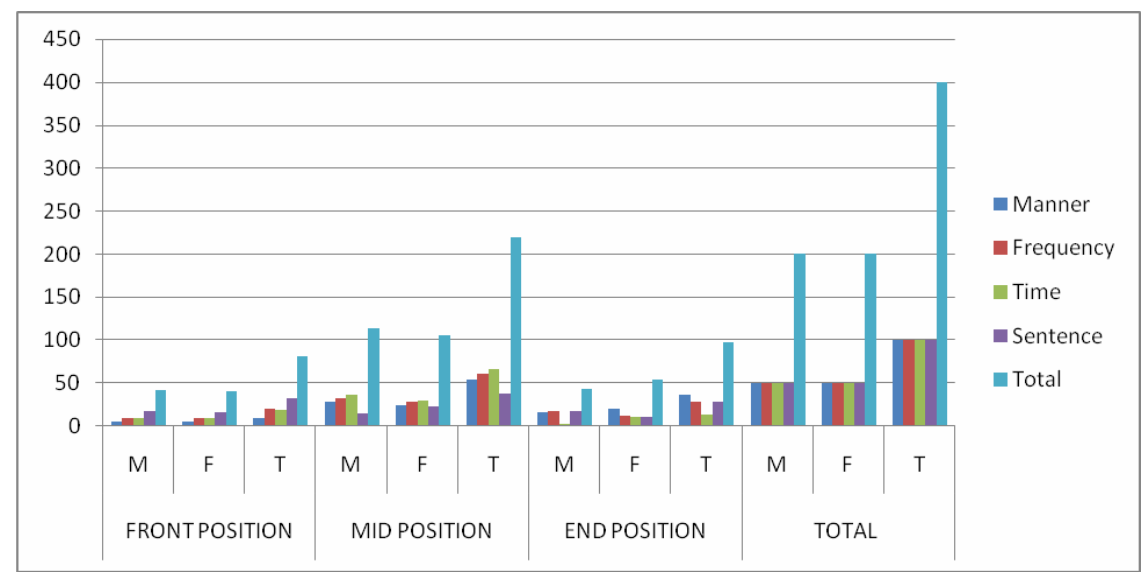

Fig 1: A Histogram showing students' placement of adverbials

The same information is here given in the form of a pie chart to reinforce the impression already obtained.

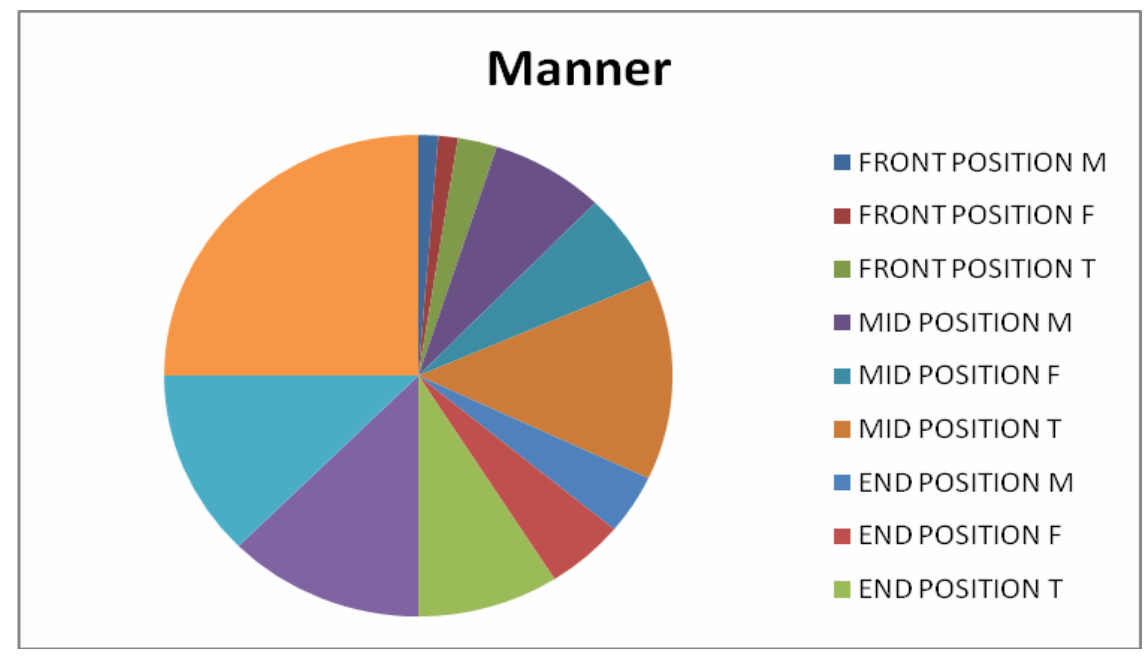

Fig 2: A pie chart showing students' placement of adverbials. 


\section{Error Density}

This aspect of the analysis looks at the nature and density of errors committed by the undergraduate students. Concerning the identification of adverbial types, it can be inferred from Table 1 that twelve male students had one error, eight had two, six had three and two had four. The female students, on the other hand, had a slightly different result. Sixteen had one error, five had two and one had three. When both male and female students were put together the result stood as twenty-eight getting one error, thirteen getting two, seven getting three and two getting four. The information is given in Table 4 below in which the total number of responses as against the number of errors has been computed to obtain the percentage error.

Table 4: Students' density of errors in the use of adverbials

\begin{tabular}{|l|l|l|l|}
\hline & MALE & FEMALE & TOTAL \\
\hline Number of Response & 300 & 300 & 600 \\
\hline Number of Errors & 54 & 29 & 83 \\
\hline Percentage & $18 \%$ & $9.66 \%$ & $13.83 \%$ \\
\hline
\end{tabular}

The table below illustrates the density for errors in the second aspect of the task, namely the arrangement of two adverbials that occur in the same position.

Table 5: Students' density of errors according to the arrangement of adverbials

\begin{tabular}{|l|l|l|l|}
\hline & MALE & FEMALE & TOTAL \\
\hline Number of Response & 200 & 200 & 400 \\
\hline Number of Errors & 44 & 32 & 76 \\
\hline Percentage & $22 \%$ & $16 \%$ & $19 \%$ \\
\hline
\end{tabular}

It becomes obvious that the density of errors was greater with male students than with the female students. The percentage errors for male students in both exercises stood at $18 \%$ and $22 \%$ while the females' percentage errors were $9.65 \%$ and $16 \%$ respectively. Research has indicated that the males are geared towards courses and programmes involving calculations while the females veered towards reading-based courses and programmes (Magshudi, 2007; Anamuah-Mensah et al., 2007; Lee et al., 1995). 


\section{Further Remarks}

Table 1 shows the result of the response to the first six task items designed to test the students' knowledge of the various adverbial types. It became obvious from the table that sixty per cent $(60 \%)$ of the students from each faculty could correctly identify four of the six adverbial types involved in the task. The error density given in Table 4 indicated a low error percentage of 18 for the male students from Arts. There was even a lower density of 9.66 for the female students from Education. The total error density for the one hundred respondents stood at $13.83 \%$. This was very commendable as it indicated that the students knew the adverbial types. The source of students' errors in the first section could be traced to the 'degree' and sentence adverbials. It is obvious that some of the students confused these two adverbial types.

The order of arranging two adverbials that occur in the same position was a little more of a problem. Table 5 indicates that the percentage error for the male students was $22 \%$ while that of the female students was $16 \%$. Error density for the one hundred respondents in this section stood at $19 \%$. It can be observed that some of the students were not aware of the rules. The result of the third section that deals with the placement preference of mobile adverbials is very clear. One sentence each of the four adverbial types used were chosen for the analysis. Out of the four hundred responses, eight-two (82) went to front position, ninety-eight (98) in the end position and two hundred and twenty (220) in mid position. When converted, the front position had $20.5 \%$, end position had $24.5 \%$ and mid position had 55\%. This is illustrated with the histogram and the pie chart above.

Findings from the first and second sections of the data indicate that the female students from Education had a slight advantage over their male counterparts from Arts. Although the performance by students from the two faculties was commendable the differences were observable. One could easily attribute the differences in performances to the differences in the nature of the environments in which the two groups of students study. Education, as had been said earlier, is a faculty with modern facilities and a lot of books and other equipment that facilitate teaching and learning. Though Arts students faced staffing and similar other faculty problems, it could be inferred from the analysis that this had little negative effect on their performance. This finding is supported in literature. Okulicz-Kozaryn's (2013) research focused on issues dealing with readability and the proportions of adjectives. He found that adjectives used were higher in the natural sciences but lower in the social sciences while adverbs used by 
researchers in the national sciences were lower but higher in the social sciences. His findings indicated that the social scientists tended to use more adjectives and adverbs as compared to the natural sciences. In a similar work, Lei (2016) conducted a study to check on the readability of proportions of adjectives and adverbs used by the applied and natural sciences on the one hand and arts and humanities and social sciences on the other. He also came to a similar conclusion as that of Okulicz-Kozaryn (2013).

The most important aspect of the task, the placement preference of mobile adverbials, had an amazing result. Both groups of students had the same preference. The general conclusion of the exercise is that most adverbials have rules governing their placement in the declarative sentence. However, when it comes to some other types, a significant number of undergraduate students frequently, placed them in the mid position.

\section{Conclusion}

As it had been stated earlier in this paper, although students appeared to be familiar with the various adverbial categories, they also appeared to confuse the "degree" with the "sentence" categories. It is, therefore, suggested that instructors lay more emphasis on these two adverbial categories. Students must be helped to be able to recognize the difference between the following:

(a) You actually realise your mistake. (Sentence)

(b) You absolutely exhausted the topic. (Degree)

Another area of concern is the process of arranging two or more adverbials that can occur in the same position. The error density in this area was greater. Instructors of Communicative Skills should give this area the attention that it deserves. Although the adverbial is an optional clausal element, it performs a useful function by providing further information on the other clausal elements. For this reason and the fact that adverbials constitute a large proportion of grammatical items, teachers of Academic Writing in Ghana should not under-rate their usefulness and sacrifice them for the obligatory structures. The importance of English in the socio-political and the economic life of the educated Ghanaian cannot be realized without a mastery of the correct use of adverb.

This study has revealed that undergraduate students in University of Cape Coast most frequently preferred to place mobile adverbials in mid position of sentences. This means that mobile adverbials may be placed anywhere after the subject and before the main or lexical verb in the declarative sentence. As the respondents were fresh 
undergraduate students who had not had more than one-year exposure to communicative skills in English, the research finding can only be regarded as the first step in this important investigation. Further research may be directed at users of English whose inter-language is above the first-year level in the university. It is believed that when the native speakers' language is made the target of such investigation, the findings of this particular research could be part of the general study into the so-called non-native varieties of English.

\section{References}

Afrifa, G. A., Anderson, J. A. \& Ansah, G. N. (2019). The choice of English as a home language in urban Ghana. Current Issues in Language Planning, 20(4), 418-438. DOI: 10.1080/ 14664208.2019.1582947.

Anamuah-Mensah, J. Asabere-Ameyaw, A. \& Mereku, K. D. (2007). Ghanaian junior secondary school students' achievement in mathematics and science. Accra: Ministry of Education, Youth and Sports.

Appartaim, A. B. (2012). Prominence and rhythm in Ghanaian English speech: A study of parliamentary discourse. In Edu-Buandoh, D. F. \& Appartaim, A. B. Between language and literature: A festschrift for Professor Kofi EduYankson. (pp. 57-76) Cape Coast: University of Cape Coast Press.

Awuku, A. S. (2011). Adverbial placement in Ewe: A role and reference grammar perspective. Legon Journal of the Humanities, 22, 147-175.

Bamgbose, A. (1982). Standard Nigerian English: Issues of identification. In B. Kachru (Ed.). The other tongue: English across cultures. (pp. 99-111) Oxford: Pergamon.

Bamgbose, A. (1997). Non-native Englishes on trial. In M. E. Dakubu (Ed.), English in Ghana (pp. 9-22). Accra: Black Mask.

Brown, K. \& Miller, J. (1994). Syntax: A linguistic introduction to sentence structure. London: Routledge.

Dako, K. \& Quarcoo, M. A. (2017). Attitudes towards English in Ghana. Legon Journal of the Humanities, 28(1), 20-30. DOI: https:// dx.doi.org/10.4314/ljh.v28i1.3.

Gborsong, P. A. (2012). Fundamentals of communicative skills. Cape Coast: University of Cape Coast Printing Press.

Gogovi G. A. K, Gborsong, P. A \& Ocran, S. (2011). English language syntax. Cape Coast: Nyakod Printing Press

Graver, B. d. (1998). Advanced English practice. Oxford: OUP.

Hornby, S. A. (1975). A Guide to patterns and usage. Oxford: OUP. 
Kachru, B. B. (1992). Models for non-native Englishes. In Kachru, B.B. (Ed.) The other tongue: English across cultures (2 ${ }^{\text {nd }}$ edition). Illinois: University of Illinois Press.

Kachru, B. B. (Ed.) (1982). The other tongue: English across cultures. Oxford: Pergamon.

Kendall, J. (2018). Saro-Wiwa's language of dissent: Translating between African Englishes. Translation and Literature, 27, 25-52 DOI: 10.3366/tal.2018.0320.

Lee, O. Fradd, S. H. \& Sututman, F. X. (1995). Science knowledge and cognitive strategy use among culturally and linguistically diverse students. Journal of Research in Science Teaching, 32, 797-816.

Lei, L. (2016). When science meets cluttered writing: Adjectives and adverbs in academia revisited. Scientometrics, 107(3), 136172.

Lomotey, C. F. (2010). Ghanaians' realization of [Y] and its implications for English teachers. Ife Studies in English Language, 8(1), 21-33.

Magshudi, M. (2007). Learning English as a third language: A comparative study between Indian and Iranian bilinguals. Language in India, 7, 1-10.

Naji J., Subramaniam G., \& White G. (2019). New literatures in new Englishes. In New approaches to literature for language learning (pp. 171-192). Cham: Palgrave Macmillan. https:// doi.org/10.1007/978-3-030-15256-7_8.

Ngula, R. S. (2014). Corpus linguistics and language development in Ghana. Asian Journal of Humanities and Social Studies, 2(4), 522-534.

Nkansah, N. (2017). Acceptability of lexico-grammatical features of Ghanaian English. An unpublished thesis submitted to the Department of English, University of Cape Coast in partial fulfilment of the requirements for the award of an Mphil degree.

Okulicz-Kozaryn, A. (2013). Cluttered writing: Adjectives and adverbs in academia. Scientometrics, 96, 679-681.

Opoku, J. Y. \& Hanson G. (2008). An empirical investigation into the use of English as a medium of introduction in primary schools in Ghana. In A. K. Awedoba (Ed.) Universitas: An Inter-Faculty Journal (pp. 25-48). Accra: Black Mask Limited.

Owusu-Ansah, L. K. (1997). Nativisation and the maintenance of standards in non-native varieties of English. In M. E. Dakubu (Ed.), English in Ghana (pp. 22-33). Accra: Black Mask Publishers. 
Platt, J.; Weber, H.; Ho, M. L. (1984). The new Englishes. London: Routledge and Kegan Paul.

Quansah, C \& Tetteh, U. S. (2017). An analysis of the use of adverbs and adverbial clauses in the sentences of junior high school pupils in the Ashanti region of Ghana. British Journal of English Linguistics, 5(1), 44-57.

Quirk, R. \& Greenbaum, A. (1973). A university grammar of English. London: Longman.

Swan, M. (1995). Practice English usage. Oxford: OUP.

Thomson, J. A. \& Martinet, A. V. (1988). A practical English grammar. Oxford: OUP.

Tregido, P. S. (1988). English grammar in practice. London: Longman.

Truelson, C. (2017). Adverbial placement in Swedish and English translations. Unpublished degree project submitted to the Department of Language, Literature and Intercultural studies, Karlstads University.

Weinreich, U. (1953). Languages in contact: Findings and problems. New York: Linguistic Circle of New York.

Weinreich, U. (1968). Languages in contact: Findings and problems. The Hague: Mouton and Co. N.V. Publishers. 